\title{
Special Issue commentary: Specific impacts of the COVID-19 pandemic on staff and patients from racialised groups
}

\author{
Richard Thwaites ${ }^{1}$ and Saiqa $\mathrm{Naz}^{2}$ \\ ${ }^{1}$ Editor-in-Chief, the Cognitive Behaviour Therapist and First Step, Cumbria, Northumberland, Tyne and Wear NHS \\ Foundation Trust, UK and ${ }^{2}$ Doctorate in Clinical Psychology, University of Sheffield, Sheffield, UK
}

Over the course of the last year, the Cognitive Behaviour Therapist has rapidly published a range of excellent and highly appreciated papers looking at a range of issues such as working with specific disorders during the pandemic such as obsessive compulsive disorder (OCD) (Jassi et al., 2020), eating disorders (Murphy et al., 2020), social anxiety (Warnock-Parkes et al., 2020) and postintensive care unit post-traumatic stress disorder (PTSD) (Murray et al., 2020). There were also papers on how to adapt training and supervision to be delivered remotely (Cromarty et al., 2020) and how to conceptualise uncertainty within the context of the pandemic (Freeston et al., 2020). These were often rapidly written by individuals struggling with the same pandemic stresses as everyone else. We appreciate their commitment to disseminating their knowledge and guidance in such a timely way to support frontline staff and whilst dealing with the impact on their own lives.

In this commentary we wanted to highlight aspects or implications of some of these papers which may need to be considered with reference to staff or patients from racialised groups (although we may use the term BAME or BME when referring to its usage in other literature). For many individuals from racialised groups, COVID-19 is having a disproportionate impact on top of the killings of George Floyd and Breonna Taylor, which had already provided a stark repeated reminder of the many systemic inequalities within our societies. It is therefore important to make space to consider both within our clinical work.

One of the earliest of the COVID-19 Special Issue papers was on the fascinating topic of death anxiety and how this might function in the context of a pandemic (Menzies and Menzies, 2020). In the UK, Brexit had already been linked with a reported rise in the number of racist incidents (Komaromi, 2016) and Menzies and Menzies point out that:

reminders of death lead people to feel more hostile towards those of different cultural backgrounds to their own, as they are seen as a threat to one's own worldviews. Findings across a number of studies reveal that reminders of death increase stereotypical thinking about people of other races (Schimel et al., 1999), increase aggression against those who criticise one's nation (McGregor et al., 1998), and lead White participants to hold more favourable reactions to White pride advocates (Greenberg et al., 2001).

(Menzies and Menzies, 2020; p. 4)

Over the course of the pandemic, there has been growing evidence that the impact of COVID19 has more significantly impacted groups such as those already experiencing higher levels of social deprivation (Office for National Statistics, 2020a) and those from certain ethnicities 
(Office for National Statistics, 2020b). On average, Bangladeshi and Black African households have almost ten times less wealth than White British households (Khan, 2020) and Bangladeshi communities currently have the lowest recovery rates in IAPT (NHS Digital, 2020).

One of the first Special Issue papers looking at potential services responses to support NHS staff throughout the pandemic pointed out that:

The workforce of NHS services is highly diverse both in nationality and ethnicity, with one in five (20.7\%) from a Black, Asian and Minority Ethnic (BAME) background, and 13\% from overseas nations. More specifically, it is estimated that around $29.7 \%$ of medical staff, who predominantly form the 'frontline', are 'Asian', whilst 4.6\% were 'Black', 2.5\% 'Chinese' and 3.2\% 'Mixed'... This is of utmost importance for mental health services to consider when delivering mental health interventions for frontline staff. Firstly, the cultural and ethnic diversity of staff needs to be acknowledged, with appreciation of the inequality and social injustice that exists between dominant and minority groups. Individuals from minority groups are more likely to experience discrimination, adversity and trauma: all risk factors for mental health difficulties (Levinson, 2011). Furthermore, according to the Intensive Care National Audit \& Research Centre (ICNARC), BAME individuals made up $35 \%$ of approximately 2000 recorded Covid-19 cases who were hospitalised but form only $13 \%$ of the UK population (ICNARC, 2020).

(Cole et al., 2020; p. 9)

One of the most recent Special Issue papers has discussed working with moral injury in PTSD and in particular how this might be applied to health workers (Murray and Ehlers, 2021). This useful paper provides a framework and helpful clinical guidance on how to address moral injury related PTSD. The paper clearly identifies potential issues within the NHS:

At the time of writing, the COVID-19 pandemic has shone a spotlight on healthcare workers and carers who are facing ethical and moral challenges and potential moral injury (e.g. Williamson, Murphy \& Greenberg, 2020). Over-stretched health and social care services have led to challenges such as making decisions about the allocation of limited resources, staff working outside their usual roles, and staff being unable to contribute fully to their roles, such as when quarantined due to infection exposure or illness, or being hampered during emergency procedures by wearing personal protective equipment (PPE). A sense of betrayal by leaders who have inadequately prepared or supported staff facing the pandemic has been reported (Thomas \& Quilter-Pinner, 2020). These staff are also facing the additional stresses caused by the pandemic, such as separation from friends and family, inability to engage in usual coping strategies due to the 'lockdown', fears for their own health and that of vulnerable family members and, possibly, bereavements.

(Murray and Ehlers, 2021; p. 2)

One interesting question not covered within the paper is how this might interact with discrimination within the NHS. This might be significantly amplified in groups where there is already recognised discrimination and a greater risk of disciplinary action for staff such as those from racialised groups (Kline, 2014; NHS England, 2020). This is likely to be exacerbated by the more widespread current feeling of being vulnerable to the risk of prosecution for unlawful killing' when treating coronavirus patients 'in circumstances beyond their control' (Lowe, 2021). This is something that we may have to consider as therapists (and explicitly ask about) when working with individuals from these groups. Also, as therapists, supervisors and leaders, we need to consider how we contribute towards psychological safety within the services and organisations we work in to support individuals from racialised groups 
when issues such as experiences of racism or microaggressions are raised (Edmondson and Lei, 2014).

Finally, services have started to consider the impact of COVID-19 on specific communities with description of good practice by commissioners and providers:

For example, some IAPT services have been working to identify areas of inequality and need by engaging health and wellbeing boards and local councils to help lead and advise on addressing areas of social inequality (e.g. ELHCP, 2020). There has been consideration for assessments to capture any inequality, for example improving access by identifying digitally excluded populations whilst working within the COVID-19 context. There are also plans to engage patients, e.g. BAME communities and staff, where COVID-19 appears to have had a disproportionate impact and review COVID-19 effects on mental health, health and behaviour change needs.

(Skilbeck et al., 2020; p. 7)

The pandemic is not yet over, and the impact will be felt for years to come within our societies and mental health services. As CBT therapists, part of our role is to ensure equal access and work towards equal clinical outcomes for all groups within society by working in partnership with our commissioners, employers and services (often needing to press them to engage against a backdrop of under-funding and other targets). Additionally, race is a protected characteristic of the 2010 Equality Act, and therefore services are legally obliged to ensure that they are meeting the needs of racialised groups. Anecdotal feedback provides ample evidence that there is much more to be done whether as simple as collecting data on patient ethnicity and their clinical outcomes in secondary care, the need to develop a centralised resource of translated materials, and ensuring that all IAPT services implement the IAPT BAME Positive Practice Guide (Beck and Naz, 2019; Beck et al., 2019). The implementation of the IAPT BAME Positive Practice Guide will ensure that BAME communities receive appropriately early intervention for a common mental health problem rather than wait until their mental health deteriorates.

Following on from the Cognitive Behaviour Therapist Special Issue on Cultural Adaptations back in 2018 (see https://cup.org/2NlerRF), $t C B T$ remains committed to publishing clinically focused articles that improve how we deliver CBT (and also train and supervise therapists) across all cultures and backgrounds but acknowledging the current starting position which is one of structural inequalities between groups.

\section{References}

Beck, A., \& Naz, S. (2019). The need for service change and community outreach work to support trans-cultural cognitive behaviour therapy with Black and Minority Ethnic communities. the Cognitive Behaviour Therapist, 12, E1. doi: 10.1017/ S1754470X18000016

Beck, A., Naz, S., Brooks, M., \& Jankowska, M. (2019). Black, Asian and Minority Ethnic Service User Positive Practice Guide. Retrieved from: https://babcp.com/Therapists/BAME-Positive-Practice-Guide-PDF

Cole, C., Waterman, S., Stott, J., Saunders, R., Buckman, J., Pilling, S., \& Wheatley, J. (2020). Adapting IAPT services to support frontline NHS staff during the Covid-19 pandemic: the Homerton Covid Psychological Support (HCPS) pathway. the Cognitive Behaviour Therapist, 13, E12. doi: 10.1017/S1754470X20000148

Cromarty, P., Gallagher, D., \& Watson, J. (2020). Remote delivery of CBT training, clinical supervision and services: in times of crisis or business as usual. the Cognitive Behaviour Therapist, 13, E33. doi: 10.1017/S1754470X20000343

Edmondson, A.C., \& Lei, Z. (2014). Psychological safety: the history, renaissance, and future of an interpersonal construct. Annual Review of Organizational Psychology and Organizational Behavior, 1, 23-43.

Freeston, M., Tiplady, A., Mawn, L., Bottesi, G., \& Thwaites, S. (2020). Towards a model of uncertainty distress in the context of Coronavirus (COVID-19). the Cognitive Behaviour Therapist, 13, E31. doi: 10.1017/S1754470X2000029X

Khan, O. (2020). The Colour of Money. London, UK: Runnymede. https://www.runnymedetrust.org/blog/the-colour-ofmoney-race-and-economic-inequality 
Jassi, A., Shahriyarmolki, K., Taylor, T., Peile, L., Challacombe, F., Clark, B., \& Veale, D. (2020). OCD and COVID-19: a new frontier. the Cognitive Behaviour Therapist, 13, E27. doi: 10.1017/S1754470X20000318

Kline, R. (2014). The 'snowy white peaks' of the NHS: a survey of discrimination in governance and leadership and the potential impact on patient care in London and England. Middlesex University Research Depository.

Komaromi, P. (2016). Post-referendum Racism and Xenophobia: The Role of Social Media Activism in Challenging the Normalisation of Xeno-Racist Narratives. http://www.irr.org.uk/news/post-referendum-racism-and-the-importance-ofsocial-activism/

Lowe, Y. (2021). Doctors and nurses 'need more legal protection amid pandemic pressures'. The Guardian (16 January 2021$).$ Retrieved from: https://www.theguardian.com/

Menzies, R., \& Menzies, R. (2020). Death anxiety in the time of COVID-19: theoretical explanations and clinical implications. the Cognitive Behaviour Therapist, 13, E19. doi: 10.1017/S1754470X20000215

Murphy, R., Calugi, S., Cooper, Z., \& Dalle Grave, R. (2020). Challenges and opportunities for enhanced cognitive behaviour therapy (CBT-E) in light of COVID-19. the Cognitive Behaviour Therapist, 13, E14. doi: 10.1017/S1754470X20000161

Murray, H., \& Ehlers, A. (2021). Cognitive therapy for moral injury in post-traumatic stress disorder. the Cognitive Behaviour Therapist, 14, E8. doi: 10.1017/S1754470X21000040

Murray, H., Grey, N., Wild, J., Warnock-Parkes, E., Kerr, A., Clark, D., \& Ehlers, A. (2020). Cognitive therapy for posttraumatic stress disorder following critical illness and intensive care unit admission. the Cognitive Behaviour Therapist, 13, E13. doi: 10.1017/S1754470X2000015X

NHS Digital (2020). IAPT Annual Interactive Dashboard 2019-20. Retrieved from: https://digital.nhs.uk/data-andinformation/publications/statistical/psychological-therapies-annual-reports-on-the-use-of-iapt-services/annual-report2019-20

NHS England (2020). NHS Workforce Race Equality Standard (WRES). Annual Report 2019.

Office for National Statistics (2020a). Deaths involving COVID-19 by local area and socioeconomic deprivation: deaths occurring between 1 March and 17 April 2020. https://www.ons.gov.uk/peoplepopulationandcommunity/birthsdeathsandmarriages/ deaths/bulletins/deathsinvolvingcovid19bylocalareasanddeprivation/deathsoccurringbetween1marchand17april (accessed 1 February 2021).

Office for National Statistics (2020b). Updating ethnic contrasts in deaths involving the coronavirus (COVID-19), England and Wales: deaths occurring 2 March to 28 July 2020. https://www.ons.gov.uk/releases/explainingethnic backgroundcontrastsindeathsinvolvingcovid19england2ndmarchto3rdjuly2020 (accessed 1 February 2021).

Skilbeck, L., Spanton, C., \& Roylance, I. (2020). Beyond the COVID-19 pandemic: 'Learning the hard way' - adapting longterm IAPT service provision using lessons from past outbreaks. the Cognitive Behaviour Therapist, 13, E34. doi: 10.1017/ S1754470X20000379

Warnock-Parkes, E., Wild, J., Thew, G., Kerr, A., Grey, N., Stott, R., ... \& Clark, D. (2020). Treating social anxiety disorder remotely with cognitive therapy. the Cognitive Behaviour Therapist, 13, E30. doi: 10.1017/S1754470X2000032X

Cite this article: Thwaites $\mathrm{R}$ and Naz S. Special Issue commentary: Specific impacts of the COVID-19 pandemic on staff and patients from racialised groups. The Cognitive Behaviour Therapist. https://doi.org/10.1017/S1754470X21000076 